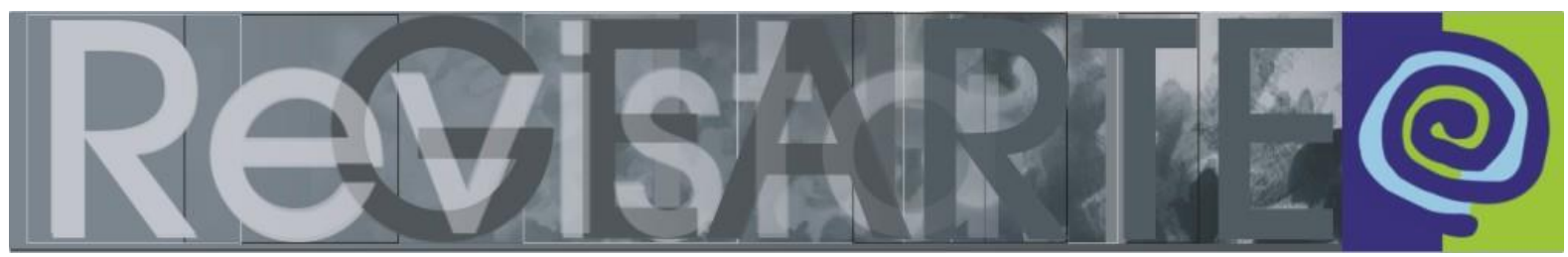

e-ISSN 2357-9854

\title{
Inquietações e mudanças na Educação Artística: mais de que nunca uma urgência
}

\author{
José Carlos de Paiva (Universidade do Porto — UP, Porto, Portugal)
}

\begin{abstract}
RESUMO - Inquietações e mudanças na Educação Artística: mais de que nunca uma urgência - O artigo escreve-se na primeira pessoa, como um exercício de reflexão, a partir da amplitude de responsabilidade política de um professor de educação artística, envolvido nas encruzilhadas de um tempo controverso onde se confronta a dignidade e imprescindibilidade da presença do artístico nas escolas com uma ofensiva ultra liberal que a pretende anular em favor de uma escola utilitarista que alimente as necessidade do sistema hegemónico e forneça sujeitos dóceis e adormecidos. As controvérsias que afrontam a dignidade humana no mundo contemporâneo exigem-nos entender que, no terreno educativo, não se procura um modelo que se lhes contraponha mas se criem possibilidades de confrontação com o novo.
\end{abstract}

PALAVRAS-CHAVE

Educação Artística. Arte. Político.

ABSTRACT - Concerns and changes in Arts Education: more than ever an urgency - The article is written in the first person, as an exercise in reflection, from the breadth of political responsibility of an arts education teacher, involved in the crossroads of a controversial time where the dignity and indispensability of the artistic presence in schools faces an ultra liberal offensive that intends to erase it, in favor of a utilitarian school that feeds the needs of the hegemonic system and provides docile and dormant subjects. The controversies that face human dignity in the contemporary world require us to understand that, in the educational field, we do not search for a model that opposes them but that we can create possibilities of confrontation with the new.

\section{KEYWORDS}

Arts Education. Art. Political.

... para ti, querida Ana Mae Barbosa no mês de abril, do Porto

Se a Arte não é tratada como um conhecimento, mas somente como um "grito da alma", não estaremos oferecendo uma educação nem no sentido cognitivo, nem um sentido emocional. Por ambas a escola deve se responsabilizar. (Ana Mae Barbosa, 2008, p. 21)

Uso a palavra para compor meus silêncios. [...] Só uso a palavra para compor meus silêncios. (Manoel de Barros, O apanhador de desperdícios)

O impulso para a escrita deste artigo não resulta da intenção de propagandear as minhas ideias, mas apenas de um esforço inquietante para melhor me esclarecer e melhor entender o terreno que piso, numa revolta com os efeitos dos dispositivos de poder sobre mim. A escrita sempre foi para mim um lugar de procura de transferência 
das questões que me confundem para um plano de esclarecimento, reconhecendo que, nela, estou a revelar as minhas fragilidades para leitores que ultrapassam as minhas insuficiências, numa responsabilidade acrescida por as escrever em voz alta. Apresentarei, assim, não o que penso e o que tenho para difundir, mas a partilha da procura de lhes acrescentar reflexão, perseguido Deleuze (2012, p. 158) "pensar é experimentar e problematizar. O saber, o poder e o si são a tripla raiz de uma problematização do pensamento."

Escreverei sobre o lugar onde coloco os pés, na Educação Artística, condição de privilégio por nele ser possível e desejável encarar a utopia da própria impossibilidade: de cada um construir a cultura de si; de se fortalecer o campo de pertença ao comum; de se entender o mundo; de nele criar interferência; de ampliar a consciência crítica e de espevitar a inventividade; etc.

Lugar de privilégio ameaçado, perante a ofensiva ultra liberal que pretende anular este campo educativo, congelando a irreverência que dele se pode soltar na promoção de experiências educativas significativas, onde se forjem presenças cidadãs críticas e intervenientes na luta agonística pela democracia radical.

[...] a obra poética não pode receber a lei sob nenhuma de suas formas, quer ela seja política, moral, humana ou não, provisória ou eterna, nenhuma decisão que a limite, nenhuma intimação que lhe ponha domicílio (BLANCHOT, 2013, p. 39).

Reconheço que o que sou capaz de entender de mim e do que me rodeia, resulta de muitos mergulhos realizados num infinito oceano de escritas, percorridas como modo de ler o como fui produzindo sentido às experiências de vida por que fui passando, numa extensão diversificada de contextos e de cenários. Também das cicatrizes produzidas nos enfrentamentos políticos, nas dificuldades e nas tristezas de uma impotência verificada pela falta de sucesso na maioria das lutas travadas e da insuficiência do êxito conquistado. Em grande parte, o ânimo do que me preenche, se solta da resiliência, e resulta do relacionamento com (felizmente) muitos amigos, mestres e camaradas, também com adversários de ideias, que revelaram, todos eles, a dimensão do significado da ética, da cooperação, da solidariedade, enfim, da luta pelo comum. 
Sou hoje, portanto, o resultado do que antecede este exercício de escrita, de enfrentamento das angústias permanentes com que encaro o que sou e o que faço. Acrescento, no sentido de esclarecer a natureza do título do artigo e na franqueza que me compõe, a adesão deste artigo à necessidade de espalhar a necessidade de "Inquietações e mudanças no ensino da arte" (BARBOSA, 2008).

Esta escrita é assinada por um professor de uma vida inteira, no território da educação artística. Uma longa caminhada por vários graus de ensino, pela "formação de adultos", no "ensino fundamental", no "ensino técnico" e no "ensino profissional", no "ensino artístico especializado", no "ensino superior", no litoral e no interior de Portugal, na Guiné Bissau, em Moçambique, no Brasil e em Cabo Verde. Percurso longo e diverso perseguindo modos de suspensão da autoridade disciplinadora que o poder do cargo me conferia, na procura de estabelecer um relacionamento educativo que permitisse aos sujeitos singulares a construção de suas subjectividades, na denúncia do poder protagonizado pelos dispositivos educativos que integro. "O mundo não é. O mundo está sendo", no ensinou Freire (2004, p. 79).

Procura complexa, em certo sentido esquizofrénica, pela pertensão impotente de no interior dos dispositivos de autoridade e disciplina querer exercer a inversão dos resultados. Ilusão perseguida através do reconhecimento da necessidade de manter uma vigilância permanente perante o que fui sendo, recusando o tipo de individualização que nos foi imposto durante séculos no Ocidente, que foi impedindo outras formas de subjectividade e, em grande dimensão, forçando a racionalidade que nos compõe. E uma atenção permanente para não transformar as "verdades naturalizadas" em comportamentos e discursos, mas as confrontar com a pertinência crítica, mesmo sabendo, como diz Baudrillard (1998, p. 60), que "não é possível escaparmos à nossa própria cultura".

Entende-se, assim, que a grande questão não está apenas em promover forças e modos de resistência política, ética e cultural ao aparato globalizado que restringe o exercício da liberdade e subjuga e condiciona a construção das subjectividades, mas, simultaneamente, erradicar em nós próprios essas submissões. 
profunda e contemplativa. A cultura pressupõe um espaço propiciador da atenção profunda (HAN, 2014, p. 26).

Esta escrita é de hoje, mergulhada nos acontecimentos preocupantes que inundam um quotidiano onde não se distingue o verdadeiro do falso e nos obriga a um alerta permanente e acutilante sobre o que nos é "apresentado".

O fascínio pelo progresso e o otimismo de um futuro democrático anunciado pela modernidade, desapareceram perante o fracasso do "mundo ocidental", resultado do próprio insucesso da globalização, desequilibrada pela ganância do "poder financeiro" escondido e incógnito, que manipula governos e dita as agressivas políticas neoliberais que vão arrasando a democracia e toldando a vida dos trabalhadores e dos excluídos. Fracasso comprovado, entre outras evidências, pelo medo generalizado com que hoje se teme o amanhã.

Tudo se está tornando paradoxal na encruzilhado dos tempos em que vivemos, onde até mesmo os progressos civilizacionais alcançados e ainda em movimento estão a ser colocados em causa, anulados numa tentativa vil, reaccionária e ignóbil de estabelecer um poder discricionário e insensível perante a pobreza e a exclusão e de intencional desvalorização social do trabalho.

Ao ponto de a liberdade, ideia nova e recente, estar já em vias de se apagar
dos costumes e das consciências, e de a mundialização liberal estar em vias
de se realizar exactamente no modo inverso: a de uma mundialização policial,
de um controlo total, de um terror pela segurança, O desregramento acaba
num máximo de constrangimentos e de restrições, equivalente à de uma
sociedade fundamentalista (BAUDRILLARD, 2002, p. 39).

Este movimento politicamente reacionário, da mundialização, não se isola no terreno financeiro, alastra para a cultura, onde os dispositivos a que pertencemos nos seduzem para neles nos naturalizarmos, mobilizados na anulação de um estado de alerta que deveria ser a única possibilidade de conferir ao modo como nos construímos a rejeição lúcida ao que nos é imposto e proposto. Perante o medo e a insegurança de vida instalada, o enredo sedutor que nos envolve e nos engana, parecendo que nos oferece o "conforto", a tranquila "integração social", e a possibilidade de acesso ao êxito ou mesmo ao estrelato, tenta a docilidade, o nosso adormecimento ou a desalentada desistência de nós mesmos. 
Sendo professor, não posso deixar de prestar atenção ao modo como sou enredado nessa teia de mistificação informativa, na voracidade da vida "permitida" que me força a agir como "empreendedor" cego na procura de algum sucesso pessoal e presença acolhida no aparato social. Reconhecendo que o meu "sucesso" é medido em "rankings de produção profissional", onde se medem os resultados e o modo como promovo o "sucesso" dos alunos, numa grelha de "avaliação" onde os indicadores são a eficiência na sua "formatação" às "metas" e "objectivos curriculares" configurados perante interesses vinculados à 'reprodução do existente", à aquietação comportamental, à docilidade cultural. Ora, preciso de identificar as tecnologias de disciplina e de autoridade a que não posso escapar, que me forçam a comportamentos que minha vontade nega, para ser capaz de as afrontar com a reflexão crítica agonística e acutilante, procurando as brechas existentes e as possibilidades de exercícios indisciplinados e insubordinados.

La 'lógica cultural', a la que obedece hoy el arte contemporáneo, surge de la
combinación de nuevas técnicas, de los medios de comunicación y del
mercado massivo. Ella logra conciliar el individualismo de massas y la
participación colectiva en el sistema de gestión de los bienes culturales. Ante
ello, el arte contemporáneo, incluso el más provocativo o extravagante, no
parece estar en condiciones de adoptar una posición crítica, en verdad
distanciada, frente a ese sistema (JIMENEZ, 2010, p. 35).

Neste pensar alto que representa esta escrita, não poderei ladear o vínculo de minha vida e de minhas inquietações à Arte, terreno que piso e de onde ganha sentido a Educação Artística onde me inscrevo como professor e como investigador. Se bem que a arte, ao longo de sua história tenha acompanhado positivamente o poder e os poderosos, ela nunca deixou de irradiar imanências de insubordinação social e cultural. Hoje, mais do que nunca, são múltiplas e diversas as formas de entender as práticas artísticas, e os artistas assumem a sua actividade com vinculações ao "mercado" e integração no "campo da arte" de modos muito distintos, de formas positivas e submissas ou críticas e irreverentes.

A separação da arte dos caminhos de sua instrumentalização, positiva ou crítica, face aos "poderes hegemónicos", e a naturalização da arte pela arte, move-a para um espaço isolado, distinto do comum, separando para dentro de si as instâncias 
de sua legitimação, não conferindo possibilidades de serem questionados socialmente os regimes de verdade com que se autolegitimam.

Também a atração pela notoriedade que é oferecida ao artista, de inscrever a sua prática artística em procedimentos "aceitáveis" ou comercializados num mercado especulativo, ou consagrada oficialmente num "espaço público" emparedado e privatizado pelos valores hegemónicos, congela bem cedo, em particular, os ímpetos críticos e criativos dos jovens artistas e entontece as leituras pelo que se passa.

É perante a encruzilhada da arte contemporânea, esquizofrénica perante a esquizofrenia dos tempos, que temos de entender a Educação Artística, não a deixando fixar num terreno de sacralização da arte, não aceitando a procura nas crianças e nos jovens das suas genialidades "artísticas", não estimulando uma adoração acrítica do que se apresenta nas exposições, nas bienais, ou nos Museu. exercício da arte não se realiza numa dimensão singular, mas em sentido diverso, complexo, contraditório e mesmo conflitual, não devendo, assim, ser assumida como um uno, mistificado e isolado. A sua complexidade e contradições, devem ser evidenciadas, entendendo-se o sentido com que, na sua diversidade ela afeta o mundo e a dimensão em que esta por ele é afetada. $O$ destino nunca faltou às outras culturas, enquanto nós, nas sociedades ocidentais, somos órfãos dele (BAUDRILLARD, 1998, p. 33).

A dimensão dos excluídos, dos assassinados-sem-nome, dos sem-emprego-esem-esperança, dos refugiados sem-espaço-e-sem-água, dos resíduos-sem-nome-esem-terra, dos novos-remediados, ultrapassa todas as previsões, situa-se numa dimensão desesperante para quem desacredita no que é mostrado e constrói a sua percepção crítica analisando atentamente as representações dos dominantes hegemónicos e Ihes contrapõe uma prática agonística, e não se cansa de lutar por uma possibilidade de haver um aberto (AGAMBEN, 2011), no tempo que há-de vir (AGAMBEN, 1993).

Volto aqui a escrever em voz alta que as complexidades do presente, que deveriam mobilizar um estado de atenção permanente, uma cruzada contra o adormecimento global, numa perspetiva de se entenderem as possibilidades de um 
futuro outro, de um aberto. Este desejo confesso, em si já instigante, entende a importância de se criarem debates agonísticos, no dia-a-dia, dentro das instituições, e tentar mobilizar, no terreno singular da Arte e da Educação Artística uma vinculação ao político, valorizando o sentido da Arte como de provocação social, campo de irreverência face ao que se apresenta como naturalizado ou inquestionável.

A grande ofensiva ultra liberal contra a Educação Artística, a Filosofia, e todos os terrenos de produção de pensamento, correspondem às dinâmicas políticas introduzidas a partir dos interesses do secreto "mundo financeiro", que tolhem de modo radical o futuro do comum.

Nessa dimensão, promove-se um entendimento da Educação Artística, não como um espaço para a aprendizagem contemplativa da Arte (do que ela foi e é) mas como um terreno de acção, de possibilidades de conferir aos alunos experiências significativas pelo artístico, pela partilha do "pensar", do "fazer", e do "fazer pensar", modos onde o artístico promove a interferência no social e desencadeia em cada um um conhecimento de si e valoriza a necessidade do comum.

A Educação Artística soube já, pela lucidez e abnegação de muitos professores, numa geografia alargada do nosso planeta, conquistar um lugar no sistema de ensino, onde as aprendizagens se estabelecem para cada aluno, onde a experiência partilhada do "fazer" possibilita ao aluno o conhecimento de sie se oferece à construção de si (FOUCAULT, 2017).

No limite do que conheço, foi relevante no Ocidente, no século $X X$, 0 crescimento do reconhecimento social pela Educação Artística (Read, Efland, Elliot, Dewey, Atkinson, Hernández,...), e assumiu relevo internacional o modo e a dimensão como no Brasil (Ana Mae, Varela, Pedrosa, Frange, ...) se expandiu na largura dos vastos territórios o movimento de Arte/Educação. Na África que usa a língua portuguesa, em particular em Cabo Verde e em Moçambique, acompanho o esforço de criação de instituições de ensino superior de arte, com implicações na formação de professores na área da Educação Artística, de onde irradiam novos espaços de incorporação nos currículos escolares desta área. 
A dimensão do movimento criado de consolidação da presença da Educação Artística no sistema de ensino, permitiu entender a dimensão educativa que a escola adquire com a incorporação desta área, e perspectiva, na dimensão da capacidade de avaliação e reflexão sobre o caminho percorrido, novas possibilidades da escola realizar a sua missão como entidade produtora da construção de possibilidades outras de futuro.

É perante uma rota em aberto que o caminho iniciado nos oferece, que se movem atuais decisões governativas de o barrar e anular, que têm de mobilizar a nossa revolta e a indignação social, alimentada por uma capacidade renovada de refrescar e inovar as práticas de educação artística, ainda demasiado agarradas aos valores da modernidade, aos sistemas de racionalidade que nos fazem agir nas rotinas em que agimos, à presença de narrativas de salvação e de atribuição à Educação Artística de vinculações aos poderes mágicos e transformadores da arte, à sua excepcionalidade, e a processos para a distinção social.

É preciso estar atento, prestar atenção crítica aos movimentos neo liberais, que pretendem um regresso a um tempo onde a Arte não tinha expressão autónoma no "discurso público" (SCOTT, 2013), prestar atenção crítica aos movimentos de governação que querem matar a presença do fazer artístico na escola, anulando a possibilidade de os alunos obterem o exercício experiencial propiciador da construção de si, impedindo que os alunos entendam as amarras existentes ao despontar de suas singularidades e pratiquem a irreverência e a insubordinação, perante o redutor e castrante exercício dos poderes disciplinares. Há muito receio nas medidas sucessivas que são introduzidas por muitos governos no sistema de ensino, correspondendo a um medo de que mesmo a fragilidade da Educação Artística aprisionada nas rotinas e na burocracia do sistema escolar, não sejam suficientes para estancar o desenvolvimento do ato educativo como um exercício de liberdade, como um lugar de afetação à vida.

Mas sejamos claros no modo de pensar alto da escrita deste artigo, porque muito nos diz respeito a nós próprios, à nossa atuação e à nossa intervenção crítica. O exercício de atenção anteriormente evocado, se entendido como opção assumida, por cada um de nós, professores, implica um esforço contínuo de suspensão do 
exercício do nosso poder, do modo como movemos os "regimes de verdade", para uma procura atenta de fortalecimento de relações educativas onde a velha postura do "mestre" (RANCIÈRE, 2010) seja radicalmente enterrada, substituída por um espaço horizontal de partilha, onde, todos sejam "aprendizes", e, assim, se permita o exercício criativo da liberdade e do artístico.

O exercício do poder disciplinador que nos integra, não está apenas presente no visível de nossa ação educativa, onde lidamos com os dispositivos que a escola organiza e nas relações educativas que alimenta, mas no invisível, na dimensão que povoa os modos subliminares, no olhar, no indizível, e por se terem transposto para o modo como os alunos, em si, os vivem. Que encontro promovemos entre o que se ensina e o que o aluno tem interesse e curiosidade em saber?, que espaço educativo permitimos para "o-que-acontecer", para o "não-programado"?, será que lidamos com as crianças e os jovens como sujeitos por inteiro, ou os tratamos como "seresmenores"?, porque consideramos o nosso "gosto" e a nossa "moral" num outro patamar?, saberemos nós professores "olhar-melhor"?, porque as crianças têm de estar "bem-sentadas"?, que valor disciplinador atribuímos à classificação dos trabalhos, aos exames?, entendemos a necessidade das crianças e dos jovens lidarem com os seus corpos, libertando-os das pressões repressivas que são exercidas?, e o toque no corpo e do corpo?, e a sexualidade?, e etc., etc.

[...] la creación de una hegemonía y ver por qué los artistas pueden desempeñar un papel importante en la subversión de la hegemonía dominante. En nuestras posdemocracias, en las que celebra un consenso pospolítico como gran avance para la democracia, las praticas artísticas críticas pueden desbaratar la imagen agradable que el capitalismo de las grandes empresas está intentando difundir, al situar en primer plano su carácter represivo, y también pueden contribuir, de muy diversas formas, a la construción de nuevas subjectividades. Esa es la razón por la que las considero una dimensión decisiva del proyecto democrático radical (MOUFFE, 2007, p. 70).

Considere-se aqui a Arte, não como um campo sagrado onde se exibem as genialidades dos artistas em terrenos de uma excepcionalidade que os coloca fora e acima dos condicionalismos humanos, mas como um território de profanação, onde a atenção às perplexidades do mundo contemporâneo promove eventos e sobre ele age, criando interferências de onde emanam com o comum possibilidades de relacionamentos sensíveis, críticos e políticos. 
Entende-se que a Arte, na atualidade, não é apenas uma manifestação humana que alimenta os processos de valorização e de especulação do capital, que integra e alimenta um estruturado aparato cultural, que torna dóceis e contemplativos os "públicos" a quem se exige, promovendo um estatuto social de "admiração", que, assim, favorece os poderes hegemónicos (como foi acontecendo ao longo da sua história). Sustenta-se a inscrição da Arte num espaço informado sobre a actualidade, que pode promover a produção agonística de conhecimento, geradora de novos modos de relacionamento social e de apropriação do espaço público, para um comum.

Nesse sentido persegue-se um entendimento da Educação Artística como um terreno de ação implicada na atenção sobre o que acontece e o que nos cerca, na reflexão crítica ao que se destina a cada um na promoção de um conhecimento de si, na construção de um relacionamento de si para consigo, do corpo e a partir do corpo. Uma ação mergulhada no artístico, na partilha do sensível (RANCIÈRE, 2004), promotora de experiências significativas (LARROSA, 2014) que irradiem confiança na capacidade de "fazer" e, assim, de afetar o circundante. Esta postura afasta da Educação Artística as visões instrumentalistas, que a amarram ao desenvolvimento da personalidade e a encerram num lugar excepcional de promoção de uma cidadania pré-configurada e de uma cultura formatada. Postura que ilude a similitude, enquanto tecnologia disciplinar de regulação, da Educação Artística (seja das expressões, da educação visual, educação musical ou arte dramática), da cultura visual, do desenho, ...), das outras áreas disciplinares. A escola é a Escola.

Mas o "fazer" pode e deve ser bem diferente, através da promoção de um território colaborativo, entre os alunos, os professores, os artistas e a comunidade, onde a experimentação dos vocábulários, das gramáticas do olhar, os modos de comunicação e de expressão, seja dominante num tempo privilegiado. Essa diferença, que será sempre a invenção de uma diferença, apenas pode resultar se formos capazes de entender o que nos amarra aos territórios naturalizados da arte e da educação artística, se formos capazes de nos re-pensar.

Não existe uma floresta enquanto ambiente objectivamente determinado: existe uma floresta-para-o-guarda-florestal, uma floresta-para-o-caçador, uma floresta-para-o-botânico, uma floresta-para-o-viajante, uma florestapara-o-amigo-da-natureza, uma floresta-para-o-lenhador e, enfim, uma 
floresta de contos na qual se perde o Capuchinho Vermelho. (AGAMBEN, 2011, p. 61).

Transportar para a educação artística o entendimento da Arte como um terreno de controvérsia entre o alinhamento com os poderes dominantes como tecnologia moral, disciplinar e económica, e como tecnologia de distinção social, ou, noutro alinhamento com a procura de posicionamentos agonísticos imanentes da possibilidade de se edificarem outras circunstâncias sociais. E neste prisma tornar evidente a imprescindibilidade do exercício do artístico como espaço de descoberta e construção de sujeitos interferentes no quotidiano.

Essa imprecindibilidade tem de ser defendida de modo a não serem permitidos retrocessos no caminho percorrido e a não se consentirem medidas que coloquem a Educação Artística num segundo plano face às restantes áreas de aprendizagem curricular, em todos os graus do ensino.

Estarei nessa luta, entre muitos, perseguindo meus "mestres".

A época da pressa não tem aroma. $O$ aroma do tempo é uma manifestação da duração (HAN, 2014, p. 61-62).

\section{Referências}

AGAMBEN, Giorgio. A Comunidade que vem. Tradução de António Guerreiro. Lisboa: Editorial Presença, 1993.

AGAMBEN, Giorgio. O Aberto: o homem e o animal. Tradução de André Dias e Ana Bigotte Vieira. Lisboa: Edições 70, 2011.

BARBOSA, Ana Mae (Org.). Mutações do conceito e da prática. In: BARBOSA, Ana Mae. Inquietações e mudanças no ensino da arte. São Paulo: Cortez Editora, 2008.

BAUDRILLARD, Jean. O paroxista indiferente. Tradução de Clara Pimentel. Lisboa: Edições 70, 1998.

BAUDRILLARD, Jean. O espírito do terrorismo. Tradução de Fernanda Bernardo. Porto: Campo das Letras, 2002.

BLANCHOT, Maurice. O livro por vir. Tradução de Leyla Perrone-Moisés. São Paulo: Martins Fontes, 2013.

DELEUZE, Gilles. Foucault. Tradução de Pedro Elói Duarte. Lisboa: Edições 70, 2012.

FOUCAULT, Michel. O que é a crítica? seguido de A cultura de si. Tradução de pedro Elói Duarte. Lisboa: Edições Texto \& Grafia, 2017.

FREIRE, Paulo. Pedagogia do oprimido. Rio de Janeiro: Paz e Terra, 2004.

HAN, Byung-Chul. A sociedade do cansaço. Tradução de Gilda Lopes Encarnação. Lisboa: Relógio D"Água, 2014. 
JIMENEZ, Marc. La querella del arte contemporáneo. Tradução de Helder Cardoso. Buenos Aires: Amorrortu Editores, 2010.

LARROSA, Jorge. Tremores: escritos sobre experiência. Belo Horizonte: Autêntica, 2014.

MOUFFE, Chantal. Prácticas artísticas y democracia agonística. Barcelona: Universidade Autónoma de Barcelona, 2007.

RANCIÈRE, Jacques. O mestre ignorante: cinco lições sobre a emancipação intelectual. Tradução de Maria Correia. Mangualde: Edições Pedago, 2010.

RANCIÈRE, Jacques. The politics of aesthetics. London: Bloomsbury, 2004.

SCOTT, James C. A dominação e a arte da resistência: discursos ocultos. Tradução de Pedro Serras Pereira. Lisboa: Terra Livre, 2013.

\section{José Carlos de Paiva}

É Doutor em Pintura, Mestre em Arte Multimédia, Graduado em Artes Plásticas, pela Faculdade de Belas Artes da Universidade do Porto. É professor na área da Educação Artística e Investigador no Instituto de Investigação em Arte, Design e Sociedade (i2ADS). Diretor na Faculdade de Belas Artes da Universidade do Porto. Tem percurso múltiplo por vários caminhos, aparentemente dispersos, mas relacionados numa atitude transversal de intervenção crítica no tecido social e atenção globalizante. Coordenador do "movimento intercultural IDENTIDADES", a partir do qual realiza ações interculturais, de índole artístico e cultural com comunidades em Moçambique, Brasil, Cabo Verde e Portugal.

E-mail: jpaiva@fba.up.pt

Currículo: http://jcpaiva.pt/?q=node/1

Recebido em 9 de março de 2017 Aceito em 20 de maio de 2017 